\title{
Potentiometric determination of Enrofloxacin using PVC and coated graphite sensors
}

\author{
Fathy M Salama, Khalid A Attia, Ahmed A Abouserie, Ahmed El-Olemy and Ebrahim Abolmagd* \\ Pharmaceutical Analytical Chemistry Department, Faculty of Pharmacy, Al-Azhar University, 11751, Nasr City, Cairo, Egypt
}

\begin{abstract}
A novel approach for the determination of Enrofloxacin (ENR) in its pure form and pharmaceutical formulation is presented. Two ion selective electrode sensors were designed for determination of enrofloxacin namely; ENR-PVC sensor and ENR-Coated graphite sensor. The sensors are based on the ion association complexes of ENR cation with sodium tetra phenyl borate (ENR-TPB) counter anions as ion exchange sites using dioctylphathalate (DOP) as plasticizer. The sensors are used for determination of ENR, in its pure form and in pharmaceutical preparation. Validation of the method shows suitability of the proposed sensors for use in the quality control assessment of ENR and for its routine analysis. The results obtained were statistically compared to reference method and there was no significant difference between the proposed methods and the reference methods regarding the accuracy and precision. The method was validated according to ICH guidelines and the results were satisfactory.
\end{abstract}

\section{Introduction}

The ion-selective electrode is defined as an electrode that can generate a difference in electrical potential between itself and a reference electrode, the output potential is proportional to the amount or concentration of the selected ion in the solution [1-2].

Modern ion - selective electrodes are based on membranes, across which material transport occurs, this material transport, includes both neutral and charged complex species or simple ions and electrons and leads to electrostatic potential differences across membranes. These so, called membrane potentials reflect both composition and activities of ions in the exterior phase. The ion-selective electrode is capable of measuring selectivity and activity of a given ion regardless of other ions present in solution [1-4].

Ion-selective electrodes can be classified according to the type and composition of the responsive membrane into glass electrodes, solidstate electrodes, liquid membrane electrodes, coated wire electrodes, gas sensing electrodes and enzyme substrate electrodes [5].

Potentiometric detection based on ion selective electrodes offers the advantages of speed and ease of preparation, fast response time, reasonable selectivity, wide linear dynamic range, online measurement and low cost [6].

The most widely used solid membrane electrodes are the plasticized poly (vinyl chloride), (PVC) electrodes which are based on the formation of ion -associates between drugs and counter ions, then the formed ion-associate was used together with PVC and a suitable plasticizer in preparation of the membrane electrode. On the other hand, liquid membranes are formed from immiscible liquids that selectively bond certain ions. The liquid ion-exchanger may be retained in a porous inert solid support which separates the liquid electrode inner solution from the test solution [7-9].

Coated graphite sensor, in which the membrane is cast onto solidlike graphite, can be used as long as the matrix of the membrane which does not react with the internal wire. In the classical coated graphite design, a conductor is directly coated with an appropriate ion selective polymer membrane usually poly (vinyl chloride), poly (vinyl benzyl chloride) or poly (acrylic acid) to form an electrode system that is sensitive to electrolyte concentrations. The advantage of using coated graphite sensor is that it can be used in small volume of sample, simple design (absence of internal solution), mechanical flexibility and the possibility of miniaturization and micro fabrication [10].

Ion-selective electrodes have been extensively used in the detection of pharmaceutical compounds [11-17].

Enrofloxacin is 1-Cyclopropyl-7-(4-ethyl-1-piperazinyl)-6-fluoro1,4-dihydro4-oxo-3-quinoline carboxylic acid. It is pale yellow crystals, slightly sol in water at $\mathrm{p}^{\mathrm{H}} 7$ [18] (Figure 1).

Enrofloxacin is a second-generation fluoroquinolone antibacterial drug that act by inhibition of deoxyribonucleic acid (DNA) gyrase, thus inhibiting both DNA and ribonucleic acid (RNA) synthesis. It has activity against some Gram-positive aerobes such as staphylococci, and a wide range of Gram-negative bacilli and cocci, and other organisms such as mycoplasma, and chlamydia. It has been used in the treatment of osteomyelitis, sinus infections, otitis, difficult soft tissue infections, peritonitis, and pleuritis or pneumonia [19].

The literature review revealed that, several analytical methods have been reported for determination of ENR in pure form and pharmaceutical preparation using spectrophotometry [20-27], spectrofluorimetry [27-32], electrochemical [33-35], Capillary electrophoresis [36], and HPLC [37-41].

${ }^{\star}$ Correspondence to: Ebrahim Abolmagd, Pharmaceutical Analytical Chemistry Department, Faculty of Pharmacy, Al-Azhar University, 11751, Nasr City, Cairo, Egypt, E-mail: Eb.Abolmagd@yahoo.com

Key words: enrofloxacin, $P V C$, coated graphite, potentiometry

Received: April 14, 2018; Accepted: May 25, 2018; Published: June 02, 2018 
<smiles>CCN1CCN(c2cc3c(cc2F)c(=O)c(C(=O)O)cn3C2CC2)CC1</smiles>

M. Formula $\mathrm{C}_{19} \mathrm{H}_{22} \mathrm{FN}_{3} \mathrm{O}_{3}$

Figure 1. Molecular Structure of Enrofloxacin

So, the main aim of the present work is to design and prepare two ion selective electrodes, ENR-PVC sensor and ENR-Coated graphite sensor for determination of ENR in bulk powder and pharmaceutical preparation.

\section{Experimental}

\section{Materials}

- Pure sample: Pure enrofloxacin (100.41\%) was kindly supplied by Eva vet Pharma Company, Al-Mahalla Al-Kubra, Al-Gharbia, Egypt.

- Pharmaceutical preparation: Enro-flox $10 \%^{\circ}$ sterile solution for veterinary injection; labelled to contain $100 \mathrm{mg} \mathrm{mL}-1$; B. No. (1/910/14) manufactured by Eva vet pharma company for manufacturing and production of veterinary drugs, Al-Mahalla AlKubra, Al-Gharbia, Egypt. It was purchased from local veterinary drug store.

- Methanol, tetrahydrofuran, dioctylphathalate (DOP), and poly (vinyl chloride) (PVC) of high relative molecular weight (SigmaAldrich, Germany).

- Sodium tetraphenylborate (Sigma-Aldrich, Germany), prepared as $10^{-2} \mathrm{M}$ aqueous solution.

- Glucose, glycine, sucrose, urea, potassium chloride, calcium chloride, magnesium chloride, sodium chloride and nickel chloride (El-Nasr Company, Egypt), prepared as $10^{-3} \mathrm{M}$ aqueous solution.

- Sodium hydroxide (El-Nasr Company, Egypt), prepared as $0.1 \mathrm{~N}$ aqueous solution.

- Hydrochloric acid (El-Nasr Company, Egypt), prepared as $0.1 \mathrm{~N}$ aqueous solution.

- Monobasic potassium phosphate, potassium chloride, boric acid, glacial acetic acid and sodium acetate tri-hydrate (El-Nasr Company, Egypt).

- The water used throughout the procedures was double distilled.

- Buffers of different $\mathrm{pH}$ values prepared as prescribed in US pharmacopeia [42]:Hydrochloric acid buffer, $\mathrm{pH} 2$.

1. Hydrochloric acid buffer, $\mathrm{pH} 2$.

2. Acetate buffer $\mathrm{pH}$ range from 4 to 5.5 .

3. Phosphate buffer $\mathrm{pH}$ range from 6 to 8 .

4. Alkaline borate buffer $\mathrm{pH}$ ranges from 8 to 10 .

\section{Apparatus}

- Jenway $\mathrm{pH}$ meter 3510 (USA) with $\mathrm{Ag} / \mathrm{AgCl}$ reference electrode no 924017-LO3-Q11C.

- Bandelin sonorox, Rx 510 S, magnetic stirrer (Hungarian).

\section{Standard solutions}

A stock standard solution of ENR $\left(10^{-2} \mathrm{M}\right)$ was prepared by dissolving $0.359 \mathrm{~g}$ of the drug powder in $1 \mathrm{~mL} \mathrm{HCl}$ then add $49 \mathrm{~mL}$ of water and completed to $100 \mathrm{~mL}$ with water. Different working solutions of varying strengths ranging from $\left(10^{-6}\right.$ to $\left.10^{-3} \mathrm{M}\right)$ were prepared by suitable dilution from the stock standard solution with water.

\section{Pharmaceutical sample preparation}

Content of one vial (100 mL) of Enro-flox 10\% sterile solution for veterinary injection; labelled to contain $100 \mathrm{mg} \mathrm{mL}^{-1}$ were transferred to $100 \mathrm{~mL}$ volumetric flask. A volume equivalent to $0.359 \mathrm{gm}$ of ENR were transferred into $100-\mathrm{ml}$ volumetric flask and completed to volume with the water to obtain a solution labelled to contain $10^{-2} \mathrm{M}$ of ENR.

\section{Procedures}

\section{Preparation of ENR-PVC membrane sensor}

- Preparation of the ion association complex:

The ion association complex, (ENR-TPB) was prepared by mixing of $50 \mathrm{ml}$ of $10^{-2} \mathrm{M}$ of both ENR and sodium tetraphenylborate solutions. The resulting precipitate was left in contact with their mother liquor for $6 \mathrm{~h}$, then the precipitate was filtered and washed thoroughly with distilled water and left to dry at room temperature for $24 \mathrm{~h}$.

\section{- Preparation of the membrane:}

In a glass petri dish (5-cm diameter), $90 \mathrm{mg}$ of DOP was thoroughly mixed with $90 \mathrm{mg}$ of PVC and $20 \mathrm{mg}$ of ENR-TPB. The mixture was dissolved in $7 \mathrm{~mL}$ of tetrahydrofuran. The petri dish was then covered with a Whitman No. 3 filter paper and left to stand overnight to allow for solvent evaporation at room temperature. A master membrane with a thickness of $0.1 \mathrm{~mm}$ was obtained.

- Electrode assembly:

From the master membrane, an $8 \mathrm{~mm}$ diameter disk was cut out from the prepared membrane and glued using tetrahydrofuran to a transposable PVC tip that was clipped into the end of the electrode glass part. The resulting electrode body was filled with equal portions of $10^{-2}$ $\mathrm{M} \mathrm{KCl}$ and $10^{-2} \mathrm{M}$ ENR. The prepared sensor was preconditioned by soaking in $10^{-2} \mathrm{M}$ drug solution for $4 \mathrm{~h}$. When not in use, the sensor was stored in air.

\section{Preparation of ENR-Coated graphite sensor}

- Preparation of the ion association complex:

The ion association complex, enrofloxacin tetraphenylborate (ENR-TPB) was prepared by mixing of $50 \mathrm{ml}$ of $10^{-2} \mathrm{M}$ of both ENR and sodium tetraphenylborate solutions. The resulting precipitate was left in contact with their mother liquor for $6 \mathrm{~h}$, then the precipitate was filtered and washed thoroughly with distilled water and left to dry at room temperature for $24 \mathrm{~h}$.

\section{- Preparation of the membrane:}

In a glass petri dish (5-cm diameter), $90 \mathrm{mg}$ of DOP was thoroughly mixed with $90 \mathrm{mg}$ of PVC and $20 \mathrm{mg}$ of ENR-TPB. The mixture was 
dissolved in $7 \mathrm{ml}$ of tetrahydrofuran and homogenized thoroughly. The solvent was slowly evaporated at room temperature until oily concentrated mixture was obtained.

- Electrode assembly:

It was prepared using commercial graphite bar $(2.5 \mathrm{~cm}$ length an, 3 $\mathrm{mm}$ diameter). One end of the bar was used for connection, while the other was dipped in the electro active membrane mixture. The process was repeated several times until a layer of a proper thickness were formed covering the terminal end of graphite bar. The electrode was left standing at room temperature to dry. The uncoated end of the graphite rod was sealed in a poly tetra ethylene tube; the tube was filled with metallic mercury into which a copper wire was dipped. The prepared sensor was preconditioned by soaking in $10^{-2} \mathrm{M}$ drug solution for $6 \mathrm{~h}$. When not in use, the sensor was stored in air.

\section{Potential measurement conditions of the proposed sensors}

The electrochemical system can be represented as following:

- For ENR-PVC membrane sensor: internal reference electrode/ internal filling solution/ PVC membrane/ test solution/ external reference electrode.

- For sofosbuvir coated graphite: reference electrode / test solution / graphite electrode.

- $\mathrm{pH}$ range: 2-8 for ENR-PVC membrane sensor and 2-10 for ENRCoated graphite sensor.

- Soaking time: $4 \mathrm{~h}$ for ENR-PVC membrane sensor and $6 \mathrm{~h}$ for ENRCoated graphite sensor.

- Response time: $40 \mathrm{~s}$ for ENR-PVC membrane sensor and $50 \mathrm{~s}$ for ENR-Coated graphite sensor.

- Sensor stability: 4 weeks for ENR-PVC membrane sensor and 2 weeks for ENR-Coated graphite sensor.

\section{Sensors calibration}

The conditioned sensors were immersed in conjunction with Ag/ $\mathrm{AgCl}$ reference electrode in the solutions of ENR in the range of $10^{-6}$ to $10^{-2} \mathrm{M}$. They could equilibrate while stirring until achieving constant reading of the potentiometer. Then, the electromotive force values were recorded within $\pm 1 \mathrm{mV}$. Calibration graphs were plotted that related the recorded electrode potential values versus the negative logarithmic value of the drug concentration.

\section{Results and discussion}

Electrochemical techniques are powerful and versatile analytical techniques that offer high sensitivity, accuracy, and precision as well as a large linear dynamic range, with relatively low-cost instrumentation [2].

In the present study two types of ion selective membrane electrodes, PVC membrane and coated graphite sensors have been constructed for determination of ENR. The methods are since ENR behave as a cation with an anionic type of ion exchanger such as tetraphenylborate to prepare water insoluble association complex using precipitationbased technique. The resulting precipitates have low solubility product, suitable grain size and physically compatible with the matrix.

\section{Performance characteristics of the developed sensors:}

The electrochemical performance of the investigated sensors was evaluated according to IUPAC recommendation data [4].
Calibrations were carried out by immersing the developed sensors in conjunction with $\mathrm{Ag} / \mathrm{AgCl}$ reference electrode in solutions of ENR in the concentration range of $10^{-6}$ to $10^{-2} \mathrm{M}$. The potential displayed by the proposed sensors for constructive measurements of the standard drug solutions in the same day and from day to day did not vary by more than $\pm 1 \mathrm{mV}$. Calibration slopes did not change by more than \pm 1 $\mathrm{mV} /$ decade concentration over a period of 2 weeks. The performance characteristics of the proposed sensors were summarized in Table 1.

The profile of the potential in $\mathrm{mV}$ versus negative logarithmic molar concentration of ENR for the investigated sensors was plotted as shown in Figure 2.

\section{Optimization of the sensors composition}

Effect of ion association complex percentage: The ion association complex is the most important part of an ion selective sensor. It is the electro active ingredient which is responsible for the selective recognition of the ion in the developed sensor.

\section{ENR-PVC membrane sensor}

The main components of a PVC membrane sensor are ion association complex, PVC and plasticizer. For the preparation of the membrane, the ion association complex, plasticizer and PVC should be taken in the appropriate percentage-weight ratios to improve the performance of the developed sensor. ENR-TPB was prepared and tested as a modifier for the proposed sensor. It was studied by varying the percentages of the ion association complex, while keeping the percentages of the PVC and the plasticizer equal 1:1 as shown in Table 2. The sensor made of $10 \%(\mathrm{w} / \mathrm{w})$ of ENR-TPB exhibited the exhibited a near Nernstian slope of $58.09 \mathrm{mV} /$ decade.

\section{ENR-Coated graphite sensor}

The ion association complex, ENR-TPB, was prepared and tested as a modifier for the proposed sensor. It was studied by varying the percentages of the ion association complex, while keeping the percentages of the PVC and the plasticizer equal 1:1 as shown in Table 2. The sensor made of $10 \%(\mathrm{w} / \mathrm{w})$ of ENR-TPB exhibited a near Nernstian slope of $57.88 \mathrm{mV} /$ decade.

\section{Effect of soaking time}

Freshly prepared sensors must be soaked to activate the surface of the membrane to form an infinitesimally thin gel layer at which ion exchange occurs. The investigated sensors were soaked in $10^{-2} \mathrm{M}$ solution of the corresponding drug. Calibration graphs were constructed for the

Table 1. The performance characteristics of the proposed described sensors

\begin{tabular}{|c|c|c|c|}
\hline \multicolumn{2}{|c|}{ Parameter } & PVC sensor & Coated graphite sensor \\
\hline \multicolumn{2}{|c|}{$\begin{array}{l}\text { - Regression equation } \\
\text { - Slope (b) } \\
\text { - Intercept (a) }\end{array}$} & $\begin{array}{c}y^{\mathrm{a}}=b^{\mathrm{b}} x+a \\
-58.09 \\
213.44\end{array}$ & $\begin{array}{c}y^{\mathrm{a}}=b^{\mathrm{b}} x+a \\
-57.88 \\
255.19\end{array}$ \\
\hline \multicolumn{2}{|c|}{ Coefficient of determination $\left(\mathrm{r}^{2}\right)$} & 0.9995 & 0.9996 \\
\hline \multicolumn{2}{|c|}{ Linearity range $(\mathrm{M})$} & $10^{-5}-10^{-2}$ & $10^{-5}-10^{-2}$ \\
\hline \multicolumn{2}{|c|}{ Working $\mathrm{pH}$ range } & \multicolumn{2}{|r|}{$2-8$} \\
\hline \multicolumn{2}{|c|}{ Response time (s) } & 40 & 50 \\
\hline \multicolumn{2}{|c|}{ LOD (M) } & $8.2 \times 10^{-6}$ & $8.8 \times 10^{-6}$ \\
\hline \multicolumn{2}{|c|}{ Stability (weeks) } & 4 & 2 \\
\hline \multicolumn{2}{|c|}{ Accuracy $(\% \mathrm{R})^{\mathrm{c}}$} & 98.07 & 98.61 \\
\hline \multirow{2}{*}{ Precision $(\% \mathrm{RSD}){ }^{\mathrm{c}}$} & Repeatability & 0.518 & 0.438 \\
\hline & Intermediate precision & 0.824 & 0.733 \\
\hline
\end{tabular}

$y_{b}^{a}$ is the recorded sensor potential.

$x$ is the molar concentration of the drug.

${ }^{c}$ Values for 3 determinations of 3 different concentrations. 
Table 2. Optimization of the membrane composition (w/w \%) of the PVC membrane sensor and coated graphite sensor

\begin{tabular}{|c|c|c|c|c|c|c|}
\hline \multirow{2}{*}{ Sensor } & \multicolumn{3}{|c|}{ Composition \% (w/w) } & \multirow{2}{*}{$\begin{array}{l}\text { Linearity range } \\
\text { (M) }\end{array}$} & \multirow{2}{*}{ Slope (mV/decade) } & \multirow{2}{*}{ r2 } \\
\hline & ENR-TPB & PVC & DOP & & & \\
\hline \multirow{4}{*}{$\begin{array}{c}\text { PVC } \\
\text { membrane sensor }\end{array}$} & 4 & 48 & 48 & $1 \times 10-5-1 \times 10-2$ & -54.31 & 0.9984 \\
\hline & 8 & 46 & 46 & $1 \times 10-5-1 \times 10-2$ & -55.42 & 0.9991 \\
\hline & 10 & 45 & 45 & $1 \times 10-5-1 \times 10-2$ & -58.09 & 0.9995 \\
\hline & 12 & 44 & 44 & $1 \times 10-5-1 \times 10-2$ & -56.77 & 0.9995 \\
\hline \multirow{6}{*}{$\begin{array}{c}\text { Coated } \\
\text { graphite sensor }\end{array}$} & \multicolumn{3}{|c|}{ Composition \% (w/w) } & Linearity rang & & \\
\hline & ENR-TPB & PVC & DOP & (M) & Slope (mV/decade) & r2 \\
\hline & 4 & 48 & 48 & $1 \times 10-5-1 \times 10-2$ & -53.68 & 0.9989 \\
\hline & 8 & 46 & 46 & $1 \times 10-5-1 \times 10-2$ & -55.05 & 0.9993 \\
\hline & 10 & 45 & 45 & $1 \times 10-5-1 \times 10-2$ & -57.88 & 0.9996 \\
\hline & 12 & 44 & 44 & $1 \times 10-5-1 \times 10-2$ & -56.07 & 0.9994 \\
\hline
\end{tabular}

sensor after different time intervals $(0,2,4,6,8$ and $12 \mathrm{~h})$ till the slope of the calibration graph deviated largely from the Nernstian value and the sensor. The results indicated that the optimum soaking time was $4 \mathrm{~h}$ for ENR-PVC membrane sensor and $6 \mathrm{~h}$ for the ENR-Coated graphite sensor as shown in Table 3.

\section{Effect of $\mathbf{p H}$}

The stability of the potential readings was investigated over a wide $\mathrm{pH}$ range (2-12) to determine the working $\mathrm{pH}$ range of the proposed sensors. The investigations were performed in $10^{-2}$ and $10^{-3} \mathrm{M}$ of ENR solutions. The potential obtained at each $\mathrm{pH}$ value was recorded. Representative curves for the effect of $\mathrm{pH}$ on the proposed sensors are shown in Figure 3. For ENR-PVC membrane sensor the potential remained constant in the $\mathrm{pH}$ range (2-10) whereas in the case of ENRCoated graphite sensor the potential remained unchanged in the range (2-8).

\section{Sensors selectivity}

The influence of the related interfering compounds on the response of the investigated sensors towards the drug was investigated. The separate solution method (SSM) was applied based on measuring the potential of $10^{-3} \mathrm{M}$ solution of each drug and the interfering ions separately. Then the selectivity coefficients were calculated by applying the following equation [43]:

$$
K_{\text {Durg }, J^{+z}}^{\text {pot }}=\frac{E_{2}-E_{1}}{S}+\log [\text { drug }]-\log \left[J^{+z}\right]^{\frac{1}{z}}
$$

Where E1 and E2 are the electrode potential of $10^{-3} \mathrm{M}$ solution of each of investigated drug and interferent ion $\left[\mathrm{J}^{+2}\right]$, respectively, and $\mathrm{S}$ is the slope of calibration curve. The interfering compounds were; potassium chloride, calcium chloride, magnesium chloride, sodium chloride, nickel chloride, glucose, urea, glycine and sucrose.

The results of the calculated selectivity coefficients indicated that the proposed sensors were highly selective towards the studied drugs as shown in Table 4.

\section{Response time of the proposed sensors}

For analytical applications, the response time of the prepared sensor is of critical importance. The average time required for the electrode to reach a steady potential response within $\pm 1 \mathrm{mV}$ of the final equilibrium value after successive immersion of a series of the drug solutions, each having a 10-fold difference in concentration, was investigated. Stable responses were achieved within $40 \mathrm{~s}$ for ENR-PVC membrane sensor and $50 \mathrm{~s}$ for ENR-Coated graphite sensor as shown in Table 1.

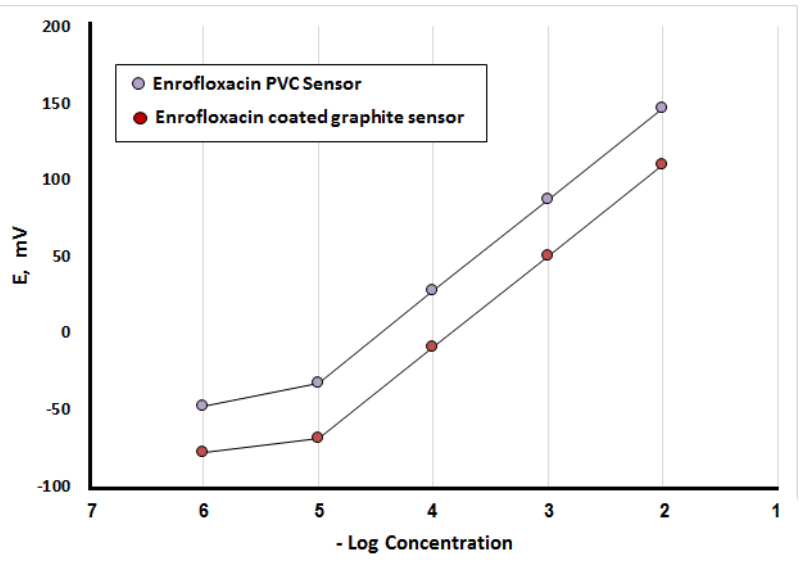

Figure 2. Profile of the potential in $\mathrm{mV} /-$ Log molar concentration of ENR using PVC and coated graphite membrane sensors

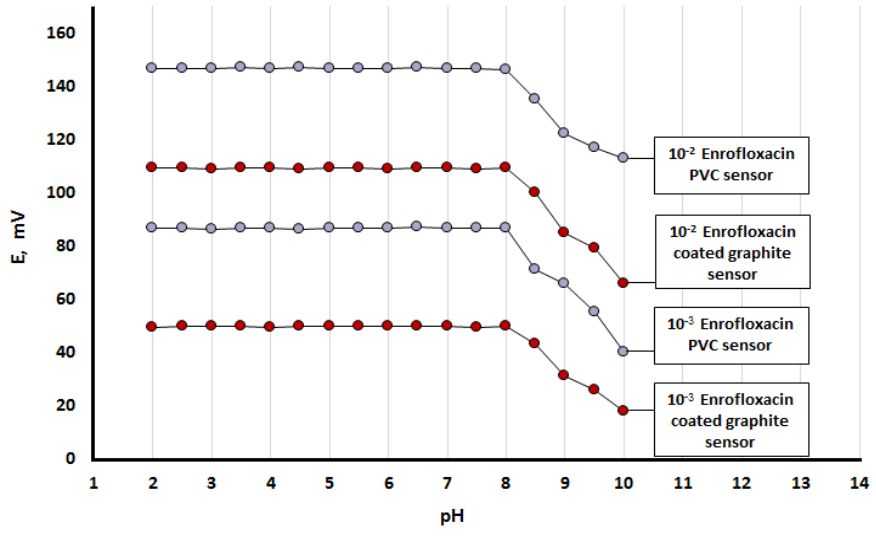

Figure 3. Effect of $\mathrm{pH}$ on the response of ENR using PVC and coated graphite sensors

\section{Methods Validation [4, 44-45]}

Linearity and range: Under the described experimental conditions, the calibration graph for each sensor was constructed by plotting the recorded sensor potential versus negative logarithmic value of the drug concentration. The regression plots were found to be linear over the range of $10^{-5}-10^{-2} \mathrm{M}$ for both sensors, as shown in Figures $2 \& 3$.

Limit of detection (LOD): Measured by interception of the extrapolated arms of Figures $2 \& 3$. It was found to be $8.2 \times 10^{-6} \mathrm{M}$ for PVC membrane sensor and $8.8 \times 10^{-6} \mathrm{M}$ for coated graphite sensor. The small values of LOD indicate good sensitivity of the described sensors. The results are given in Table 1. 
Accuracy and precision: Accuracy of the described methods, calculated as the mean percent recovery (\%R), was assessed by applying the described procedure for triplicate determination of three concentration levels covering the linearity range of each drug $\left(10^{-2}\right.$, $10^{-3}$ and $\left.10^{-4} \mathrm{M}\right)$. The results in Table 1 indicated the accuracy of the proposed method.

Precision of the methods, calculated as the percent of relative standard deviation (\%RSD), was assessed by triplicate determination of three concentration levels covering the linearity range of each drug $\left(10^{-2}, 10^{-3}\right.$ and $\left.10^{-4} \mathrm{M}\right)$ within one day for repeatability and on three successive days for Intermediate precision. The small values of \%RSD indicated high precision of the method as shown in Table 1.

\section{Application of the method to pharmaceutical sample}

The proposed method was applied for the selective determination of enrofloxacin in presence of its acid induced degradate in Enro-Flox $10 \%$ sterile solution for veterinary injection. Satisfactory results were obtained in good agreement with the label claim. The obtained results were statistically compared to those obtained by the reported method [46]. No significant differences were found by applying t-test and F-test at $95 \%$ confidence level [47], indicating good accuracy and precision of the proposed methods for the analysis of the studied drugs in its pharmaceutical dosage form, as shown in Table 5.

Table 3. Effect of soaking time on the described sensors

\begin{tabular}{|c|c|c|}
\hline Soaking time/hour & PVC sensor & $\begin{array}{c}\text { Coated graphite } \\
\text { sensor }\end{array}$ \\
\hline 0 & -48.19 & -47.89 \\
\hline 2 & -53.62 & -49.14 \\
\hline 4 & $\mathbf{- 5 8 . 0 9}$ & -52.26 \\
\hline 6 & -56.13 & $-\mathbf{5 7 . 8 8}$ \\
\hline 8 & -54.38 & -55.43 \\
\hline 10 & -52.11 & -53.77 \\
\hline 12 & -50.87 & -52.06 \\
\hline
\end{tabular}

Table 4. Selectivity coefficients of the described sensors using separated solution method

\begin{tabular}{|c|c|c|}
\hline Interferent & $\begin{array}{c}-\log K_{\text {Durg, } J^{+z}}^{\text {pot }} \\
\text { PVC membrane sensor }\end{array}$ & $\begin{array}{c}-\log K_{\text {Durg, } J^{+z}}^{\text {pot }} \\
\text { of } \\
\text { coated graphite sensor }\end{array}$ \\
\hline Calcium chloride & 1.004 & 1.059 \\
\hline Magnesium chloride & 1.002 & 1.019 \\
\hline Sodium chloride & 1.007 & 1.091 \\
\hline Nickel chloride & 1.014 & 1.068 \\
\hline Glucose & 1.029 & 1.081 \\
\hline
\end{tabular}

Table 5. Determination of enrofloxacin in Enro-Flox $10 \%{ }^{\circledR}$ vial by the described sensors and reported method

\begin{tabular}{|c|c|c|c|}
\hline \multirow{2}{*}{ Parameters } & \multicolumn{2}{|c|}{ Sensor } & \multirow{2}{*}{$\begin{array}{l}\text { Reported } \\
\text { method } \\
\text { (94) }\end{array}$} \\
\hline & PVC & Coated graphite & \\
\hline $\mathrm{Na}$ & \multicolumn{2}{|c|}{5} & 5 \\
\hline Mean & 98.73 & 99.08 & 100.68 \\
\hline Variance & 0.506 & 0.419 & 0.595 \\
\hline$\%$ RSD & 0.702 & 0.641 & 0.766 \\
\hline Student's t-test (2.36)b & 1.481 & 0.977 & - \\
\hline F-value (6.39)b & 1.177 & 1.421 & - \\
\hline
\end{tabular}

a Number of measurements

$\mathrm{b}$ The values in parenthesis are tabulated values of " $\mathrm{t}$ "and " $\mathrm{F}$ " at $(\mathrm{P}=0.05)$.

\section{References}

1. Thomas JDR (2013) Ion-selective electrode reviews. Amsterdam: Elsevier.

2. Morf WE (2012) The principles of ion-selective electrodes and of membrane transport. Amsterdam: Elsevier.

3. Fry C, Langley S (2004) Ion-selective electrodes for biological systems. London Harwood academic publishers.

4. Buck RP, Lindner E (1994) Recommendations for nomenclature of ion-selective electrodes. Pure App Chem 66: 2527-2536.

5. Thévenot DR, Toth K, Durst RA, Wilson GS (2001) Electrochemical biosensors: recommended definitions and classification. Biosnse Bioelectron 16: 121-31.

6. Pungor E, Tóth K (1970) Ion-selective membrane electrodes. A review. Analyst 95: 625-648.

7. Moody G, Saad B, Thomas J (1988) The development of polymer matrix membranes for ion-selective electrodes. Sel Electrode Rev 10: 71.

8. Ragab MT, El-Rahman MKA, Ramadan NK, El-Ragehy NA, El-Zeany BA (2015) Novel potentiometric application for the determination of pantoprazole sodium and itopride hydrochloride in their pure and combined dosage form. Talanta 138: 28-35. [Crossref]

9. Ammar RA, Otaif H, Al-Warthan A (2012) A novel ion-selective membrane electrode for the determination of duloxetine. Anal Methods 4: 1427-1431.

10. Freiser H (1986) Coated wire ion-selective electrodes. Principles and practice. $J$ Chem Soci 82: 1217-1221.

11. Ragab MT, El-Rahman MKA, Ramadan NK, El-Ragehy NA, El-Zeany BA (2015) Novel potentiometric application for the determination of pantoprazole sodium and itopride hydrochloride in their pure and combined dosage form. Talanta 138: 28-35. [Crossref]

12. Ammar RA, Otaif H, Al-Warthan A (2012) A novel ion-selective membrane electrode for the determination of duloxetine. Anal Methods 4: 1427-1431.

13. El Gohary NA, El Nashar RM, Aboul-Enien HY (2011) Potentiometric determination of sibutramine using batch and flow injection analysis. Anal Lett 44: 241-257.

14. Abdel-Ghani NT, Hussein SH (2010) Determination of diphenylpyraline hydrochloride in pure solutions and pharmaceutical preparations using ion selective electrodes under batch and FIA conditions. Anal Lett 43: 582-602.

15. Khalil MM, Issa YM, Mohamed AG (2014) Construction and performance characterization of ion-selective electrodes for potentiometric determination of paroxetine hydrochloride in pharmaceutical preparations and biological fluids. Electroanalysis 26: 2789-2800.

16. El-Tohamy M, Razeq S, Shalaby A (2012) Electrochemical Sensors for determination of anticonvulsant drug gabapentin in bulk powder and pharmaceutical dosage forms. Int J Electrochem Sci 7: 5374-5387.

17. Amini MK, Shahrokhian S, Tangestaninejad S (1999) PVC-based Mn (III) porphyrin membrane-coated graphite electrode for determination of histidine. Anal Chem 71 2502-2505. [Crossref]

18. O'Neil MJ (2013) The Merck index: an encyclopedia of chemicals, drugs, and biologicals: RSC Publishing.

19. Martindale W, Sweetman SC (1999) Martindale: the complete drug reference: Pharmaceutical press London.

20. Mostafa S, El-Sadek M, Alla EA (2002) Spectrophotometric determination of enrofloxacin and pefloxacin through ion-pair complex formation. J Pharm Biomed Anal 28: 173-180. [Crossref]

21. Rajendraprasad N, Basavaiah K (2015) Development and Validation of New Spectrophotometric Methods to Determine Enrofloxacin in Pharmaceuticals. J App Spect 82: 513-519.

22. EL Sherif ZA (1999) Spectrophotometric determination of enrofloxacin through the formation of a binary complex with iron iii, ion-pair and charge-transfer complexation in pure and dosage forms. Anal Lett 32: 65-78

23. Mostafa S, Salama I, El-Sadek M (2002) Spectrophotometric determination of ciprofloxacin, enrofloxacin and pefloxacin through charge transfer complex formation. J Pharm Biomed Anal 27: 133-142. [Crossref] 
24. Gouda AA, Amin AS, El-Sheikh R, Yousef AG (2014) Spectrophotometric determination of gemifloxacin mesylate, moxifloxacin hydrochloride, and enrofloxacin in pharmaceutical formulations using acid dyes. J Anal Methods Chem 2014: 286379. [Crossref]

25. Rajapandi R, Aswathy SR, Sreedharran B (2016) Spectrophotometric method development and validation for estimation of enrofloxacin in pure and dosage forms. World J Pharm Res 5: 1402-1410.

26. Zhak T, Smolinska M, Korkuna O (2017) Ion-pair complexes formation between fluoroquinolone antibiotics and methyl red and their use for the extractionspectrophotometric analysis. Adsorption Sci Tech 35: 612-622.

27. El-Didamony AM, Aboelsoad MO (2014) Spectrophotometric and spectroflurimetric determinations of veterinary drug enrofloxacin in pharmaceutical formulation. Optics and Spectroscopy 117: 670-678.

28. Ulu ST (2009) Rapid and sensitive spectroflurimetric determination of enrofloxacin, levofloxacin and ofloxacin with 2,3,5,6-tetrachloro-p-benzoquinone. Spectrochim Acta A Mol Biomol Spectrosc 72: 1038-1042. [Crossref]

29. Rizk M, Belal F, Ibrahim F, Ahmed S, El-Enany N (2000) Spectrofluorimetric analysis of certain 4-quinolone in pharmaceuticals and biological fluids. Pharm Acta Helv 74: 371-377. [Crossref]

30. Salem H, Fada L, Khater W (2007) Spectrofluorimetric determination of certain fluoroquinolones through charge transfer complex formation. Am J Pharm Tox 2: 1825 .

31. Geffken D, Salem H (2006) Spectrofluorimetric study of the charge-transfer complexation of certain fluoroquinolones with 2,3,5,6-tetrafluoro-p-bezoquinone. Am J App Sci 3: 1952-1960.

32. Ballesteros O, Vílchez JL, Taoufiki J, Navalón A (2004) Determination of the antibacterial drug enrofloxacin by solid phase spectrofluorimetry. Microchimica Acta 148: $227-233$.

33. Ensaifi AA, Khayamian T, Taei M (2009) Determination of ultra-trace amount of enrofloxacin by adsorptive cathodic stripping voltammetry using copper (II) as an intermediate. Talanta 78: 942-948. [Crossref]

34. Rizk M, Belal F, Ibrahim F, Ahmed S, El-Enany NM (2000) Voltammetric analysis of certain 4-quinolones in pharmaceuticals and biological fluids. J Pharm Biomed Anal 24: 211-218. [Crossref]
35. Kamel AH, Moreira FTC, Rebelo TSR, Sales MGF (2011) Molecularly-imprinted materials for potentiometric transduction: application to the antibiotic enrofloxacin Anal Lett 44: 2107-2123.

36. Wang L, Wu X, Xie Z (2005) Determination of enrofloxacin and its metabolite ciprofloxacin by high performance capillary electrophoresis with end-column amperometric detection. J Sep Sci 28: 1143-1148. [Crossref]

37. Tauber V, Pătrut E, Chiurciu V (2015) Development and validation of an HPLC method for the determination of oxytetracycline and enrofloxacin in veterinary formulations. Medicamentul Veterinar / Veterinary Drug 9: 65-69.

38. Chakravarthy VA, Sailaja BBV, Kumar AP (2015) Stability-indicating RP-HPLC method for simultaneous estimation of enrofloxacin and its degradation products in tablet dosage forms. J Anal Methods Chem.

39. Anacleto SDS, Teixeira LS, Borges MMC, Moraes CT, Borges WDS, et al. (2017) A simple and rapid HPLC method for the multi determination of enrofloxacin, ciprofloxacin, and oxytetracycline in raw materials and veterinary pharmaceutical formulations. Current Pharm Anal 13.

40. Shanawani E, Ahmed A (1997) HPLC determination of endoxacin, norfloxacin and enrofloxacin in the presence of some related compounds. Chin Pharm J 49: 259-265.

41. e Souza MJ, Bittencourt CF, Morsch LM (2002) LC determination of enrofloxacin. $J$ Pharm Biomed Anal 28: 1195-1199. [Crossref]

42. United States Pharmacopoeia 30 and National formulary 25 (2007) Rockville (MD): United State Pharmacopoeia Convention.

43. Bakker E, Pretsch E, Bühlmann P (2000) Selectivity of potentiometric ion sensors. Anal Chem 72: 1127-1133. [Crossref]

44. International Conference on Harmonization, ICH Harmonized Tripartite Guideline (2005) Validation of analytical procedure: text and methodology, Q2 (R1). Geneva: International Conference on Harmonization.

45. Stefan RI, Aboul-Enein HY (1998) Validation criteria for developing ion-selective membrane electrodes for analysis of pharmaceuticals. Accredit Qual Assur 3: 194-196.

46. EL Sherif ZA (1999) Spectrophotometric determination of enrofloxacin through the formation of a binary complex with iron iii, ion-pair and charge-transfer complexation in pure and dosage forms. Anal Lett 32: 65-78

47. Armitage P and Berry G (1994) Statistical methods in medical research. 3rd ed. Oxford (UK): Blackwell.

Copyright: (C2018 Salama FM. This is an open-access article distributed under the terms of the Creative Commons Attribution License, which permits unrestricted use, distribution, and reproduction in any medium, provided the original author and source are credited. 